\title{
Introducción a la Sección Política Internacional
}

\section{Dra. Lía Rodriguez de la Vega Coordinadora de Sección}

La sección de este número concentra nuevamente su atención en Asia. En primer lugar, considera el episodio de alta tensión en Asia del sur, en Doklam, entre China e India y trae la cuestión de la territorialización y la construcción social del espacio a primer plano (Giménez, 1999).

En cuanto a Asia del Sur, cabe decir que esta región está dominada por la India, país que posee tres veces la población de todos los otros países del sur de Asia combinados, al tiempo que es también más poderoso en términos políticos, militaresy económicos. La región posee una cooperación regional muy débilmente institucionalizada y encuentra en la actualidad una influencia china en crecimientomuchas veces aludida a través de la estrategia china del "Collar de Perlas", contestada a su vez por India, a través de su estrategia del "Triángulo de Varuna").

La zona evidencia una relación antagónica con un componente nuclear entre India y Pakistán y diversas disputas territoriales, que elevan las tensiones en ella. Siendo una de las zonas más densamente pobladas del planeta tiene ya como una de las cuestiones de importancia la dinámica de los acuerdos sobre el uso de cursos de agua compartidos y es escenario de distintas disputas identitarias (relacionadas a distintos conflictos étnico/religiosos, iniciativas insurgentes, etc., que afectan e involucran a diversos países de la región).

Las dinámicas actuales se traducen en una estrecha relación chino- pakistaní, que suma en el presente la iniciativa de un corredor económico entre ambos, en el contexto de OBOR, al tiempo que un movimiento de contención de China, en la articulación de la relación de India-Estados Unidos-Japón.

En segundo lugar, vuelve el abordaje de la cuestión del pueblo Rohingya, de Myanmar, cuya crisis humanitaria aumentó por las circunstancias de agosto de 2017, esta vez con la toma de posición de diversos estados, incluyendo la Declaración de Bali, surgida tras el Foro Parlamentario Mundial, celebrado en Indonesia (7-9 de septiembre).

La situación compromete distintos elementos, atendiendo a que Myanmar es parte dela Asociación de Naciones del Sudeste Asiático (ASEAN), cuyos fundadores expresaron el deseo de que la ASEAN no debería interferir en los asuntos internos de los Estados miembros, lo que hizo que la organización se mantuviera en esa dirección, buscando facilitar aún más el proceso de consenso. Sin embargo, las tensiones en tal consenso se han hecho más evidentes por las nuevas circunstancias que se presentan, tales como la 
expansión de la misma ASEAN, el surgimiento de amenazas no tradicionales a la seguridad, que no se limitan al frente interno de los países sino que traspasan fronteras y también la democratización y la globalización económica, que implicanconsideración de la ética de intervención, particularmente cuando se trata de cuestiones asociadas a la violación de los derechos humanos, como en este caso (Kim y Lee, 2011).

Asia del Sudeste posee una compleja historia migratoria tanto dentro como hacia fuera de la región, relacionada a diversos factores y muchas veces de carácter irregular. Los países de la región a menudo enfrentan cuestiones relacionadas a la migración irregular asociada al trabajo, población en riesgo de desplazamiento por exclusión, persecución y/o una habilidad limitada para asegurar ingresos básicos, que permitan desarrollar una vida digna, flujos de refugiados, etc. La región posee además una ausencia de infraestructura de protección para afrontar las temáticas relativas a estas cuestiones de población (McAuliffe, 2016).

Relacionado precisamente a la cuestión migratoria en la región, el Proceso de Bali es un marco para la cooperación en todos los ámbitos de la misma (originalmente, la migración irregular, el tráfico y la trata de personas) entre los países de origen migratorio, de tránsito y de reasentamiento. Fue establecidoen la Conferencia Ministerial Regional del Proceso de Bali de 2002 y es copresidido por los gobiernos australiano e indonesio. En 2011, los gobiernos participantes concluyeron un Marco de Cooperación Regional que aunque no es vinculante, significó un avance crucial en la zona por tres motivos: 1) se reconoció que los refugiados y solicitantes de asilo poseen el derecho a la protección, enunciado novedoso para la región, atendiendo a la adopción de la Convención de 1951 sobre el Estatuto de los Refugiados, por parte de pocos estados de la zona2) se reconoció el derecho a la no devolución al país de origen, si las personas temen por su vida o temen persecución (que se corresponde con el artículo 31 de la citada convención así como la Convención sobre la Tortura y el Pacto Internacional de Derechos Civiles y Políticos)y 3) hubo discusión sobre la creación de arreglos prácticos para reflejar los principios del marco (cosa que no resulta fácil) (Davis, 2015).

La crisis humanitaria de mayo de 2015, dada por los rohingya, embarcó a los países de la región en diversas negociaciones para formular una respuesta, aunque ello se hizo por fuera de los foros y organizaciones existentes (el Proceso de Bali y ASEAN) (The Bali Process, s.f.). Si bien inicialmente los países más afectados dieron efectivamente respuesta a la ayuda necesitada y temporal recepción de la población llegada y posteriormente, Tailandia realizó un encuentro con los países de la región, organizaciones internacionales y donadores, del cual surgieron recomendaciones, las mismas no eran vinculantes, al tiempo que otros países de fuera de la región, ofrecían ayuda, aunque la misma era de carácter selectivo (McAuliffe, 2016).De igual manera, el Diálogo de Asia sobre Migración Forzada, se 
pronunció sobre el caso de los rohingya en una declaración de prensa, llamando al cese de hostilidades, a permitir la llegada de ayuda humanitaria y a adoptar un abordaje pacífico, apoyado en lo señalado por la Comisión Asesora de KoffiAnan (Dato y Puteri, 2017).

Las autoras que participan en la sección en este número, abordando los temas mencionados son Laura Gatto y Antonela Víttola, ambas de la Universidad del Salvador y miembros del Grupo de Trabajo sobre India y Asia del Sur, del Comité de Asuntos Asiáticos del Consejo Argentino para las Relaciones Internacionales.

\section{Referencias}

Dato, S. y Puteri, N. A. Y. (2017). Can the ohingya Be Saved?. Focus. Kuala Lumpur: Institute of Strategic and International Studies (ISIS) Malaysia. Recuperado de http://www.isis.org.my/files/IF 2017/ISIS Focus 4-2017.pdf

Davis, S. (2015). Time to Protect Southeast Asia's Refugees. Regional cooperation must focus more on protection solutions. TheDiplomat (12 de septiembre). Recuperado de http://thediplomat.com/2015/09/time-to-protect-southeast-asias-refugees/

Territorio, cultura e identidades. Estudios sobre las Culturas Contemporáneas 25, II, V, 9, 25-57. Recuperado de http://herzog.economia.unam.mx/academia/inae/inae5/516.pdf

Kim, H.J. y Lee, P.P. (2011). The Changing Role of Dialogue in the International Relations of Southeast Asia. Asian Survey, 51 (5), 953-970.

McAuliffe, M. (2016). Resolving Policy Conundrums. Enhancing Humanitarian Protection in Southeast Asia. Washington, DC: Migration Policy Institute.

The Bali Process (s.f.). Disponible en http://www.baliprocess.net/ 